\title{
Institutional QA System Based on Large Scale System Cybernetics
}

\author{
Dai Ren ${ }^{1}$, Xuewu Dong ${ }^{1 *}$, Kai $\mathrm{Mu}^{2}$ \\ 1Zhongyuan University of Technology, Zhengzhou, P.R. China \\ 2Henan University of science and Technology, Luoyang, P.R. China \\ dxw2053@126.com,dianneren@zzti.edu.cn
}

\begin{abstract}
Teaching quality is extremely critical to university. It is also the criterion to measure core competence. It is an eternal topic to improve teaching quality. Based on large scale system cybernetics and the influence factors of institutional teaching quality, the scientific teaching quality assurance (QA) system was to be set up. It is a large scale system and includes organization, standard, source, work and other subsystems. Each subsystem consists of multiple lower subsystems. This article first states the system is a large scale system and complex with lots of integrated factors between two related subsystems. It is necessary to use large scale system cybernetics to manage top-level system. Therefore, we can get a view point of expected system target. It is important to find institutional teaching quality with effective operation and continuous improvement.
\end{abstract}

Keywords-Institution; Teaching quality assurance system; Large scale system cybernetics; Analysis

\section{INTRODUCTION}

Modern science and technology have been greatly impact on the world due to the rapid development, especially in the field of higher education. Science and technology are dramatically influencing higher education for the achievement from teaching quality assurance, education pedagogic, management, philosophy, and so on.

In the 1960s, the U.S. management expert Feigenbaum put forward the concept of "Total Quality Management (TQM)" which began to occur in the European higher education quality assurance in the mid-1980s, and then gradually expanded to more than 80 countries and regions such as the United States, Canada, Australia, and formed higher education quality assurance movement in the 1990s which has a widespread influence in the world. Teaching quality assurance of institution is the basis of the quality assurance of higher education, all colleges and universities have started to build their own teaching quality assurance system and higher education theory workers have also carried out research to build the institutions of higher teaching quality assurance system. For example, in theory, the teaching quality of institution value selected, the definition of the concept, the relationship between the elements and elements of teaching quality assurance system, issues such as the breadth and complexity of the system, has not yet reached a consensus; In practice often according to the classical control theory construction and running the teaching quality assurance system, for system elements, structure are not according to the objective law and rely on subjective fabricate construction and operation, which made the institution teaching quality assurance system is far from reached effect. These problems are the important reasons for research angle is not broad, lack of system science, especially for lack of large-systems control theory guidance.

\section{ThE DEFINITION OF THE TEACHING QUALITY ASSURANCE SYSTEM OF INSTITUTION}

Teaching quality assurance system of institution is to ensure and to improve quality of teaching quality at the undergraduate level organization that was established, and regulatory frameworks, system management processes and resources to support the system. Including the core is to improve the quality of teaching and the goal is to train high-quality talents; we should organize the activities and functions of various aspects and departments during the teaching process, to form an organic whole where the task, responsibility and authority are all clear, and each one is able to coordinate with each other to promote the whole. Teaching quality assurance system is a branch of the institution overall management of the system, the core of their way of thinking is in management system the institution to establish the organization of its personnel training activities of the quality to be systematic, structured, continuing concern mechanism. The talent training is the basic function of institution, improve the quality of talent training is the core task of institution, the teaching work is the basic way to personnel training and the teaching quality is the basic content of the quality of talent training. In accordance with the thought of comprehensive and total quality management, the activities of all personnel of the colleges and universities are focusing on improving the quality of teaching. Therefore, the teaching quality assurance system of institution including the whole-institution approach to the vast majority of officers and various activities, which is composed of organization system, standard system, source system, work system and other subsystems. And each subsystem has multiple low-level subsystems [1].

\section{TEACHING QUALITY ASSURANCE SYSTEM OF INSTITUTION IS A LARGE SYSTEM}

The large scale system means that the system is comprehensive and large-scaled with complicated structure. Cybernetics of the general system means that it is the combination of theory for the general system and artificial intelligence. Cybernetics of the general system establishes the theory and method to find out the regulating motion by itself. It includes modern control theory, graph theory, mathematical programming and decision-making theory, and etc. The scope 
of research involves industrial technology, society, politics, economy and ecology, and so on. The management of general system mainly relates to the research of mathernmatical modeling and identification, model simplifying, structural features, steability analysis and calmness, coordination and priority control of the system itself, respectively.

Guarantee and improving the quality of teaching come to form the common goal of institutional teaching quality assurance system that a certain intrinsic link subsystem assembly. Because there are so many influencing factors that need to establish relationship between the subsystem and the whole and each subsystem. Make a partial optimal control to various subsystems and integrated the various subsystems law for a mutual coordination between the various subsystems, eventually achieve the goal of optimization overall control system. To achieve this control target need to analyze and understand the elements of the quality assurance system, organizational structure, information flow, then build and gradually improve. University teaching quality assurance system has the following characteristics:

\section{A. Huge Scale}

The teaching quality assurance system of institution includes organization system, standard system, work system, source system and other subsystems, and each subsystem has multiple low levels of sub-systems.

Organizational guarantee for the quality of teaching is organization system. Organizational system subsystem composed by the decision-making system, command system, execution system, monitoring system and other subsystems. The decision-making system is prepared by the leading body under the secretary and principal, and it also includes decision-making systems, decision support systems, and other subsystems, etc. The command system constituted by the institution in charge of teaching students, resources (including faculty, funds, facilities, books and equipment, etc.) and other leaders and functional departments, including teaching system, students work system, resource system and other subsystem, which is constituted by the multi-level subsystem. Teachers and students, teaching units constitute the execution system and the concrete implementation of the teaching quality assurance is the primary duty. The monitoring system is mainly constituted by the teaching quality supervision departments and teaching quality experts, including the evaluation system, monitoring system, and information feedback system.

The standard system is the goal of teaching quality assurance. Considerate the teaching quality have so complex multi factorial interactions that generate and apparent lag, inevitably lead to the development of teaching quality standards complex and difficult. Teaching quality standard system consists of two subsystems, the student development standards and the quality of teaching. They are also constituted by multiple low-level subsystems. For example, students development quality standards including training objectives, teaching activities, teaching objectives, the criteria for graduation and degree standard subsystem. Teaching quality standards including all kinds of quality standards of classroom teaching, practice teaching, student assessment and other indicators of teaching standards, student learning quality standards and teaching management quality standards subsystem.

The work system is the mechanism assurance of the quality of teaching. Work system including the basic operation of the teaching quality assurance mechanisms, procedures and information subsystem. Among them, the basic operation of the teaching quality assurance mechanisms subsystem including teaching quality assurance incentive and restraint mechanisms, teaching quality information gathering, processing and transmission of the operating mechanism, teaching quality evaluation mechanisms, the quality of teaching, the regulatory mechanism subsystem [2].

The source system is the primary of assurance for the teaching quality. The system constitutes faculty, related expenses, teaching facilities, teaching devices, library and other sub-systems. Each sub-system is consisted of multiple lower systems. For instance, the system of faculty is consisted by the subsystem for different discipline of catalogue, various specialty catalogue, liberal courses, basic scientific courses, professional curriculums, theoretical courses, practical courses subsystem, etc. the faculty system of learning branch is also consisted by the subsystem of literature, physics, engineering, artistic subsystem, and so on. Moreover, the subsystem of teaching facilities includes the subsystem of lecturing rooms, laboratory room, education of training base, library, play grounds, stadium, campus internet subsystem and so on. Among those subsystems, the subsystems of laboratory is constituted by the laboratory used for curriculum of specialty as well as basic scientific courses subsystem and so on, which are still constituted by the multi-low subsystem.

\section{B. Complex Structure}

Institutional Teaching quality assurance system in the complex relationship among each level subsystem. Such as the relationship of students and teachers in the two main elements of the organizational system subsystem is very complex. Although the educational psychology circle make a long time, large number of research, made a lot of research achievements, however, research on the relationship between university teachers and students still remain many deficiencies.

\section{Functional Integrity}

Colleges and universities to cultivate senior specialists talents as the goal, students are required to achieve the learning objectives, and teachers to complete the teaching objectives, management personnel to achieve management objectives, and so on. Thus, the system functions of the university teaching quality assurance system must be multifaceted and comprehensive. 


\section{Many Factors}

Teaching quality assurance system of institution is a multi-variable, multi-input, multi-output, multi-target, multi-system interference. Moreover, not only the "material" factor, but also the "people" factor, not only technical factors, but also economic factors, social factors. Possess uncertainty and ambiguity. For example, student learning, teaching, management, personnel management, and so multi-variable; students, teachers, books, equipment, and so multi-input; the quality of the course, each graduate quality multi-output; the course objectives, personnel quality are multi - target; unhealthy trends in society, institution internal interference, the temptation of the network and money and so much interference. At the same time, the traditional teaching management is relatively simple, rely on the institution's individual departments and the management of routine tasks can be completed tasks, With the With the increasing complexity of the college environment, factors affecting the quality of teaching increasing day by day, and more complicated [3].

\section{CONCLUSIONS}

The teaching quality assurance system of institution includes organization system, standard system, work system, source system and other subsystem, each subsystem is composed by multiple low-level subsystem. It is a large system scale with complex structure between the various subsystems, integrated functions, many influencing factors, therefore this is a large system, need to be controlled by the large system control method in order to achieve the desired goal of institutional teaching quality with effective operation and continuous improvement.

\section{ACKNOWLEDGEMENTS}

Our survey in this paper is supported by the Education Science Planning key topics of Henan Province.

\section{REFERENCES}

[1] Xuewu Dong, Dai Ren. Theoretical framework of standard system for institution Teaching Quality Assurance System [D]. The Fourth International Symposium on Education Management and Knowledge Innovation Engineerring. Jiaozuo, China, 2011.

[2] Xianjun Liu, Junchao Zhang. The Case of Chinese Institutional Research (The First Series) [M]. Wu han: Hua Zhong University of Science and Technology Press, 2009.(In Chinese)

[3] Chunling Wang. Study on Researching University Undergraduate Teaching Quality Assurance System [D]. Tianjin: Tianjin University, 2007.(In Chinese)

[4] Huiluo Liu. Quality Management [M]. Xi'an: Northwest Industrial University Press, 1992.(In Chinese)

[5] Yeguo Qi. The Theoretical Framework of Institutional Teaching Quality Assurance System [J]. Higher Education of Jiangsu, 2009(2).(In Chinese)

[6] Jie Wu .System Philosophy [M]. Beijing: People Press, 2008.(In Chinese)

[7] Xuesen Qian. System Science, Thinking Science and Human Science [J]. Chinese Journal of Nature, 1981(1):3-9.(In Chinese)

[8] Xuyan Tu, Cong Wang, Yanhui Guo. Large Systems Cybernetics [M]. Beijing: Beijing University of Posts and Telecommunications Publishing, 2005.(In Chinese)

[9] Jiaju Bi. Degree Standards and Quality Assurance Guidelines of the European Higher Education Area [J]. Higher Education Development and Evaluation, 2006, 22(5).(In Chinese)

[10] Yiming Gong. Quality Management [M]. Shanghai: Fudan University Press, 2000.(In Chinese) 